\title{
SOCIAL ADAPTATION OF PEOPLE WITH DISABILITIES
}

\author{
Marina Sadovski ${ }^{1}$
}

\begin{abstract}
The article discusses the idea that children with movement disorders have great potential for motor and mental development. The experiment consists of two stages. In the first stage of the experiment, the characteristics of disability in children and adolescents (between age 12 and 16) with Infantile Cerebral Palsy are determined. During this stage, two diagnostic methods, bodily "Me" and "The Color-A-Person Body Dissatisfaction Test,” are used.

In the second phase of the research program, social pedagogical aids for people with disabilities have been developed. On the basis of the experimental work, the obtained social pedagogical insights have been successfully implemented in the social adaption of disabled children.

It is determined that this method is promising to help adults and children with mobility impairment to enhance their mental well-being, attain a positive body image, express their feelings freely, interact socially using a motor component, and above all-enjoy the movements. This method can ensure the effectiveness of social adaptation for individuals with disabilities.
\end{abstract}

JEL Classification Number: O35, DOI: http://dx.doi.org/10.12955/cbup.v2.486

Keywords: socialization, adaptation, disabilities, infantile cerebral palsy, dance therapy, body consciousness

\section{Introduction}

Nowadays, social development problems in the coming generation is becoming more prominent because every year a number of disabled children increases. Currently, 1.6 million out of 40 million children living in Russia belong to the category of children with developmental disabilities. Meanwhile, the prevalence of nervous system diseases amounts to approximately 34 to 42 children per 10,000 newborns.

A congenital anomaly, nervous system diseases, and mental disorders take leading position in the structure in children's primary disability. Among neurological diseases, the main cause of children disability is infantile cerebral palsy (ICP); the prevalence of which is 2 to 2.5 cases per 1,000 children.

At the present, there also emerges the issue of social adaptation for children and teenagers suffering from musculoskeletal diseases. These diseases pose as a serious problem because their symptoms may complicate and prevent the children's ability to socially adapt to their environment and socialize with other individuals.

Social adaptation and socialization problems are presented in the works of Kibirev (2003), Kotosonova (2006), Nevirko (2000), Pavlova (2011), Pronina (2010), Romm (2003), Shilova (2002).

Social integration (from latin words “adapto," meaning to adapt, and "socium,” meaning society) is an active adaptation to the conditions of social environment through assimilation and adoption of goals, values, norms, and behavior styles existing in society (Wooley \& Roll, 1991). According to Kazakova (2010), "the essence of social adaptation of a person with disabilities is in acceptance, assimilation and reproduction of the rules of conduct, norms, values, attitudes specific to contemporary society of healthy people."

Currently, the following question becomes more and more important: "what resources and tools make it possible for people with disabilities and for the people around them to be accepted by the society in the most complete and comfortable way?”

In the process of finding solutions to this problem, we assumed that a condition for acceptance of people with disabilities and their integration into society is understanding the lack of clearly defined boundaries between the inner and outer components.

\footnotetext{
${ }^{1}$ Marina Sadovski, Belgorod State National Research University, Russian Federation, belkonferenz@mail.ru
} 
Jung (2007) confirmed that a lacking of clear separation between internal and external components, “a body without a soul does not mean anything, as well as let ourselves to accept the point of view of a soul - a soul means nothing without a body.” Through the understanding of these words, we come to the idea of increasing adaptive capability of people with special needs. The possibility of finding any sort of permanent "support point" in the spiritual substance, and, thus the upheaval of the need in work methods aimed at finding and fixing these "support points."

In this regard, it is important not to underestimate the material aspect when considering social adaptation issues of the people with special needs. In order to understand the importance of corporeity $^{2}$, it is desirable to consider the idea of a close relationship between the spiritual and physical aspects. That is the reason why the work with a moral component of a person with special needs shall be implemented through the work with their physical being. The famous Latin phrase reads, "Mens sana in corpore sano" (a sound mind in a sound body). This saying was written through Juvenal's pen, a Roman poet-satirist (approximately in $1^{\text {st }}$ century AD). Back in antiquity, special attention was paid to harmonious development of personality. The term "kalokagathia" was used in "Dialogues of Plato," the ancient Greek philosopher. This is a compound ethico-aesthetic concept-a kind of centaur, an ideal of a man, embodying the harmonious combination of physical and moral qualities (Losev, 1969).

In order to correct the defects in children with ICP, they would require both physical and mental components to rely on the experience of their own bodily awareness. There is an adjustment for the perception of the body taking into account the reality, emotional values associated with certain parts of the body, and the body itself as a whole. These are the main elements characterizing the image of a human body.

\section{Research materials and methods}

In this article, we have utilized the psychological and pedagogical research methods: analysis, synthesis, comparison, questioning, and pedagogical experimenting. The source for empirical research was the assumption that the peculiarity of the socially interactive space, depending on the image of the bodily "Me" in children and teenagers with ICP, will be manifested in socio-psychological lethargy, isolation by establishing the boundaries between oneself and the outside world, and estrangement by increasing the distance in the relationship with others.

The study was conducted on the grounds of Regional State Budgetary Institution "Rehabilitation Center for Disabled People” among children and teenagers with cerebral palsy.

\section{Research results and discussion}

The initial stage in the diagnostic study was to determine the characteristics of bodily "Me" image in children and teenagers with ICP (ages between 12 and 16). At this stage, the diagnostics methods of bodily "Me" introduced by Lybko (2008) are used along with "The Color-A-Person Body Dissatisfaction Test: stability, internal consistency, validity, and factor structure” by Wooley \& Roll (1991).

The following conclusion can be drawn from the study of bodily "Me" image in children and teenagers with ICP the: in this category of examined persons, the level of dissatisfaction with one's own body is high. They are characterized by negative attitude to the defective part of the body, which, of course, affects self-esteem and creates an unfavorable space for social interaction around them.

\footnotetext{
2 "Corporeity, as a projection of conditions and forms of communicative representations of the body as a sign and a symbol that acts as the subject of analysis in the Humanities,” (Jung, 2007).
} 
The results obtained by ascertaining experiment allowed us to see new perspectives for the study of the close relationship with external and internal components, in particular, the influence of the degree of satisfaction with body for involvement and commitment to social contacts. Further work in this direction may answer the question of how the bodily "Me" is integrated into an individual's social life.

From our viewpoint, this idea quite smoothly continues its existence in the compensation and overcompensation law by L. S. Vygotsky, an outstanding special education teacher who developed this concept from psychological trend created by the Austrian School of Adler-a psychiatrist. According to Vygotsky (2003), "every defect is not limited to an isolated loss of function, but entails a radical restructuring of the whole personality and brings to life new psychic powers, gives them a new direction.”

According to these views, handicap is a primary cause of development. Vygotsky (2003) wrote about the social adaptation problems for a person with disabilities based on the example of visually and aurally challenged children, “....and for the teacher, for a person approaching a visually challenged child with the intent to educate him, there is no blindness as direct physiological fact, but there are social consequences of this fact, which has to be taken into account.”

Thus, L.S. Vygotsky saw the elimination of social consequences of existing human limitations as a task toward the goal of social adaptation. As we see, following the thoughts of L.S. Vygotsky, the issue of fully integrating children with disabilities into society comes down to the question on the best combination of the use of psyche power preservation, social imperatives based on it, and social control on the part of the society. Vygotsky's Overcompensation law relies on the laws of dialectics: the obstacle is its driving force. Therefore, dance therapy is one of the techniques, which are actively used for social adaptation and psyche harmonization for people with disabilities (Grenlyund, 2011). It is a form of therapy that combines work from the body, movements, and emotions.

Dynamic movement to music can be regarded as an obstacle, and thus, in turn, physical activity can be a driving force, which is an overcompensation. Overcoming this obstacle both for partner with ICP and a common partner becomes another step toward erasing the boundaries between them. In this case, we (our society) are exempt from education of "relaxed by compassion and philanthropic trends" and do not focus on the "zolotnik of diseases" (an expression by L.S. Vygotsky). Moreover, we truly pass on focusing on the "two stones of health," which is preserving mental and physical powers.

In addition, the guilt of people without disabilities disappears in front of people with disabilities, in our opinion, due to the disappearance of psychological barriers in socializing with the handicapped. In the process of dance therapy, this barrier does not exist; in fact, an obstacle in mobile limitation is overcome in a dance.

In our opinion, common people without disabilities treat dance therapy classes with lively interest. It is difficult to overestimate an assistance provided by dance therapy in harmonization of body and soul of dancing people. Jung (2007) believed that the artistic experience, in which he called "active imagination," expressed, for example, in a dance, can extract unconscious desires and needs and make them available to the cathartic release and analysis.

At the second stage of the research, a program for socio-psychological follow-up for children with disabilities was developed. A group of test subjects was determined. The test subjects were briefed with the purpose of the study. All test subjects participated in the study voluntarily. The experimental work was carried out in a studio "Vanjka-vs-Tanjka," where it was possible to hold classes in dance therapy. Dance couples were formed, where one of the partners had disabilities and was in a wheelchair, while the other partner was healthy. Out of all the experimental participants, 53\% were a group of actively moving people, $13 \%$ were wheelchair-bound persons, and $13 \%$ were student 
volunteers. Classes were held twice a week for actively moving people and three times a week for wheelchair-bound persons

The structure of all dance classes is similar:

1. Warm-up; when all muscle groups and joints are warmed up, breathing is balanced and classic exercises are performed (basic feet and hand motions for persons in wheelchair). Wheelchairbound persons also acquire technical skills of using a dance wheelchair.

2. The main part of the class consists of two blocks:

a. dance moves and dance routines, followed by the staging of dance routines. Retaining the requirements to dance techniques. The head gives an opportunity to everyone to learn them at their own pace, according to their own capabilities. During this part of the class, people work out movements;

b. people dance during the second block.

3. Final stage - required remedial breathing exercises and muscle relaxation.

All dance classes contributed to an in-depth understanding of one's self, bodily "Me" of the participants; understanding the possibilities of using a body, ways of expressing feelings; establishing communication on a sensitive basis with a motor component; and, finding enjoyment in movements, which was the most important thing.

Upon completing the socio-psychological follow-up program for children with disabilities, a pole was taken and the results of which allowed us to identify emotional drivers for attending dance therapy classes. $75 \%$ of the respondents attended classes to maintain tonus; $75 \%$ of the respondents wanted to learn different types of dances; $80 \%$ of the respondents attended dance classes because they liked dancing; and, $80 \%$ of the respondents attended dance classes to lift their spirits.

\section{Conclusion}

With the number of children with disabilities continually rising, the challenges in social interaction and adaption for these children are also becoming more prevalent. We discuss some of the methodologies aimed toward helping individuals with disabilities to cope with their psychological and social limitations. Two methods were used and results analysed as part of the experiment with a strong potential for implementing them with young children with ICP to improve their motor and mental development.

The experiment results show a close relationship between spiritual and physical interactions for handicapped individuals. This fact emphasizes the influence of physical state and psychological wellbeing on the emotional driver in a disabled person and their willingness to socialize. The socioeducational support program development for people with disabilities is an effective way to deepen their understanding and enhance the mental awareness of their physical being in order to promote mental well-being, such as confidence, self-esteem, and, ultimately, acceptance.

One effective activity identified through the program is dance therapy. The results indicated that dance therapy can help reduce emotional tension, while promoting physical movement. This activity enables disabled individuals to overcome their psychological insecurity inhibiting their social interaction with other people. Not only is dance therapy an effective way for people with disabilities to socialize, but it also contributes to the harmonization of the mental and physical components of a personality. Thus, it is determined that this method is promising to help adults and children with mobility impairment to enhance their mental well-being, attain a positive body image, express their feelings freely, interact socially using a motor component, and above all—enjoy the movements. 


\section{References}

Burlachuk, L. F., \& Morozov, S. M. (1999). Dictionary—reference book on psychodiagnostics. St. Petersburg: Peter Com. Grenlyund, E. (2011). Dancing therapy. Theory, technique, practice. St. Petersburg: Speech.

Jung, C. G. (2007). Problems of the soul of our time. Retrieved from http://modernlib.ru/books/yung_karl_gustav/problemi_ dushi_nashego_vremeni/read/

Kazakova, L. A. (2010, March). Diagnostics of results of social education of children and teenagers with limited opportunities of health. Chuvash State University.

Kibirev, A. A. (2003). Forms of socialization of the identity of the neglected child in socially oriented educational space. Materials of the All-Russian scientific and practical conference. Novosibirsk.

Kotosonova, N. A. (2006). Socialization of children without parental support, in the course of game activity. $51^{\text {st }}$ Scientific and Methodical Conference of Teachers and Students on "A problem of ensuring integrity of teaching and educational process.” Stavropol.

Losev, A. F. (1969). History of an antique esthetics. Retrieved from http://royallib.ru/read/losev_aleksey/istoriya_antichnoy_ estetiki_rannyaya_klassika.html\#0.

Lybko, I. V. (2008, March). Metodika “diagnostics corporal I” [Psychological diagnostics]. Scientific and Methodical and Practical Magazine, 5-21.

Nevirko, D. D. (2000). Methodical bases of studying of socialization of the personality on the basis of the principle of the minimum universum. The personality, creativity and the present.

Nikitin, V. N. (2007). Human corporality: ontognoseologichesky analysis. Moscow: MPGU.

Pavlova, L. G. (2011, January). Early socialization of children in the conditions of modernization of Russian education.

Pronina, A. N. (2010, August). Design of space of socialization individualization of the personality in the conditions of deprivation. Siberian Pedagogical Magazine (the scientific and practical edition), Novosibirsk, 106-114.

Puzanov, B. P. (Ed). (1996). Defectology: the dictionary reference. Moscow: New school.

Romm, M. V. (2003). Social adaptation of the personality as object of the philosophical analysis. Tomsk.

Sakharov, V. G.( 2011). Diagnostics of the relation to a body. St. Petersburg: Speech.

Shilova, M. I. (2002). Socialization and education of the identity of the school student in pedagogical process. Krasnoyarsk. Vygotsky, L. S. (2003). Fundamentals of defectology. St. Petersburg.

Wooley, O. W., \& Roll, S. (1991). The Color-A-Person Body Dissatisfaction Test: stability, internal consistency, validity, and factor structure. Journal of Personality Assessment, 56(3), 395-413. 